\title{
Unilateral laminectomy approach for total resection of intradural extramedullary spinal tumor
}

Steven Awyono',

Putu Eka Mardhika²,

Tjokorda Gde Bagus Mahadewa3

Akbar Wido ${ }^{4}$,

Hizkia Lumban Gaol's, Intan Permata Wijaya ${ }^{6}$

1,2Resident of Neurosurgery Department, Faculty of Medicine, Udayana University, Sanglah General Hospital, Bali, Indonesia

${ }^{3} \mathrm{Head}$ of Spine Division, Neurosurgery Department, Faculty of Medicine, Udayana University, Sanglah General Hospital, Bali,

Indonesia

${ }^{4}$ Resident of Neurosurgery Department, Faculty of Medicine, Airlangga University, Dr. Soetomo General Hospital, Surabaya, Indonesia ${ }^{5}$ Resident of Surgery Department, Faculty of Medicine, Udayana University, Sanglah General Hospital, Bali, Indonesia

${ }^{6}$ Resident of Plastic and Reconstruction Surgery Department, Faculty of Medicine,

Udayana University, Sanglah General Hospital, Bali, Indonesia

\section{Cite this article:}

Awyono S, Mardhika PE, Mahadewa TGB, Wido A, Gaol HL, Wijaya IP. Unilateral laminectomy approach for total resection of intradural extramedullary spinal tumor. Neurologico Spinale Medico Chirurgico. 2019. 2(1): 23-26. DOI: 10.36444/nsmc.v2il.5

\begin{abstract}
Spinal tumors found in about $5-15 \%$ of the central nervous system neoplasm. Intradural-extramedullary spinal cord tumors are one of the types that usually managed with total laminectomy but with many postoperative complications. A 76-year-old woman with paraplegia caused by intradural-extramedullary intraspinal tumor at thoracic 4 level. For this patient, we performed unilateral laminectomy without any fusion or stabilization from the left side then we performed total excision of the tumor. The surgery was successfully done with fast improvement of patient condition, minimal pain after surgery, no blood transfusion needed, shorter intensive care period needed, and fast recovery time are the prominent things in this case. Three days after surgery, the patient's motoric power already improved and then the patient is permitted to go home at the fifth day.
\end{abstract}

Keywords: Unilateral Laminectomy, Spinal Tumors, Intradural-Extramedullary Tumor

\section{Introduction}

Spinal tumors are part of CNS tumor that occurs about 5-15\%. One example of an intraspinal tumor is Intradural-Extramedullary (IDEM) Spinal Tumor. ${ }^{1}$ This type is relatively common for tumors in the spinal canal account for about $40 \%$. The most common pathological types for IDEM are a meningioma, schwannoma, and neurofibroma. ${ }^{1-3}$

The most effective management for spinal tumors achieved by total laminectomy. Total laminectomy is one of the conventional technique for removing spinal tumors, and this approach still found commonly. ${ }^{4}$ Total laminectomy offers a good exposure and views for the surgeon and reported as a technique with satisfactory prognosis. However, despite many advantages offered, this technique may disrupt the stability of the spine due to damage of the posterior column and may produce neurological symptoms. ${ }^{4,5}$

Unilateral laminectomy may provide good exposure with relatively safer and fewer trauma to posterior column lead to relatively fewer side effects. ${ }^{4,6,7}$ Unilateral laminectomy preserves posterior ligaments and spinous process joint that lead to a more stable outcome of the spine postoperatively. ${ }^{3-5}$

This report describes advantages from our experiences using unilateral laminectomy for intradural-extramedullary spinal cord tumors to increase awareness about the same cases in the future and lead a better option in managing patient with the same condition.

\section{Case Report}

A 76-year-old woman, Javanese, came to our center, complained about the inability to walk or move her leg. She felt it for 3 months before came to the hospital. History of falling, beater, unconscious was denied. She said the complaints worsening in a few days. At first, she felt weak 
on both of her leg without any pain or sensation disorder. She came to Other Rural Hospital and diagnosed intradural extramedullary mass at thoracic 4 vertebrae level and then referred to Sanglah General Hospital. On the examination, blood pressure was 120/70 $\mathrm{mmHg}$, pulse rate 80 times per minute, respiratory rate 18 times per minute, temperature $36.8^{\circ} \mathrm{C}$ and pain scale was 0 out of 10 . From neurologic examination, it was found that the patient was fully alert. Then she was found to have paraplegia with flaccid type. Sensory examination and autonomous function were found to be normal. The Neurological deficit of lower extremity which was decreased of motoric power to grade zero in both lower extremities. Supporting examination such as Magnetic Resonance Imaging was taken (Figure 1). The result showed a mass on the spinal cord at thoracic level 4-5.

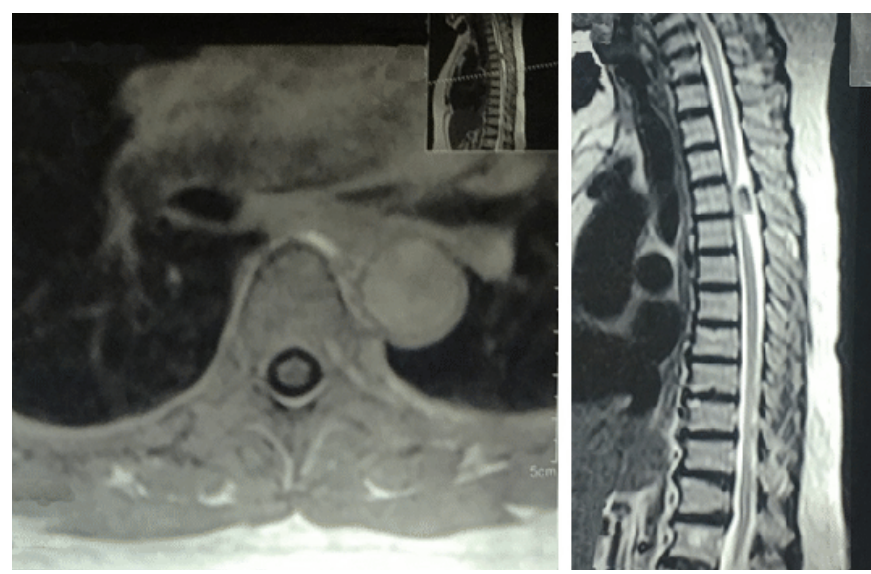

Fig 1. Pre-operation MRI revealed intraspinal tumor on thoracic 4 level

After holistic history taking, physical examination and supporting examination, the patient chosen as a candidate for unilateral laminectomy excision (without fusion and stabilization) surgery over the abnormality level. After preparation of surgery, we did an incision on the left side of the spine to expose the laminae from thoracic 3 to thoracic 5 . Then we performed a unilateral laminectomy of half posterior left side of the T4 lamina and unilateral laminectomy of half inferior left side of the T3 and a half superior left side of the T5. The patient was operated in a prone position and then tilted about $30^{\circ}$ to the right resulting in a very optimal view over the dura. Then with microscope support, we did an incision on the dura and found the tumor was intradural and extramedullary.

We perform total excision of the tumor and biopsy (Figure 2). No fusion or stabilization made because the thoracic 4 spine was still stable enough, then the surgical site was sewn layer by layer. After surgery finished, the patient admitted to the intensive care unit for one day and moved to the inpatient room. At the third day after surgery, we found progress on the lower motoric recovery. No blood transfusion was needed for the patient and the patient was permitted to go home after five days. Eight days after surgery patient came back to the hospital for the routine check-up we found some improvement, she was able to stand up alone but still couldn't walk, later on, we performed three dimensional CT scan (figure 3). Histopathological
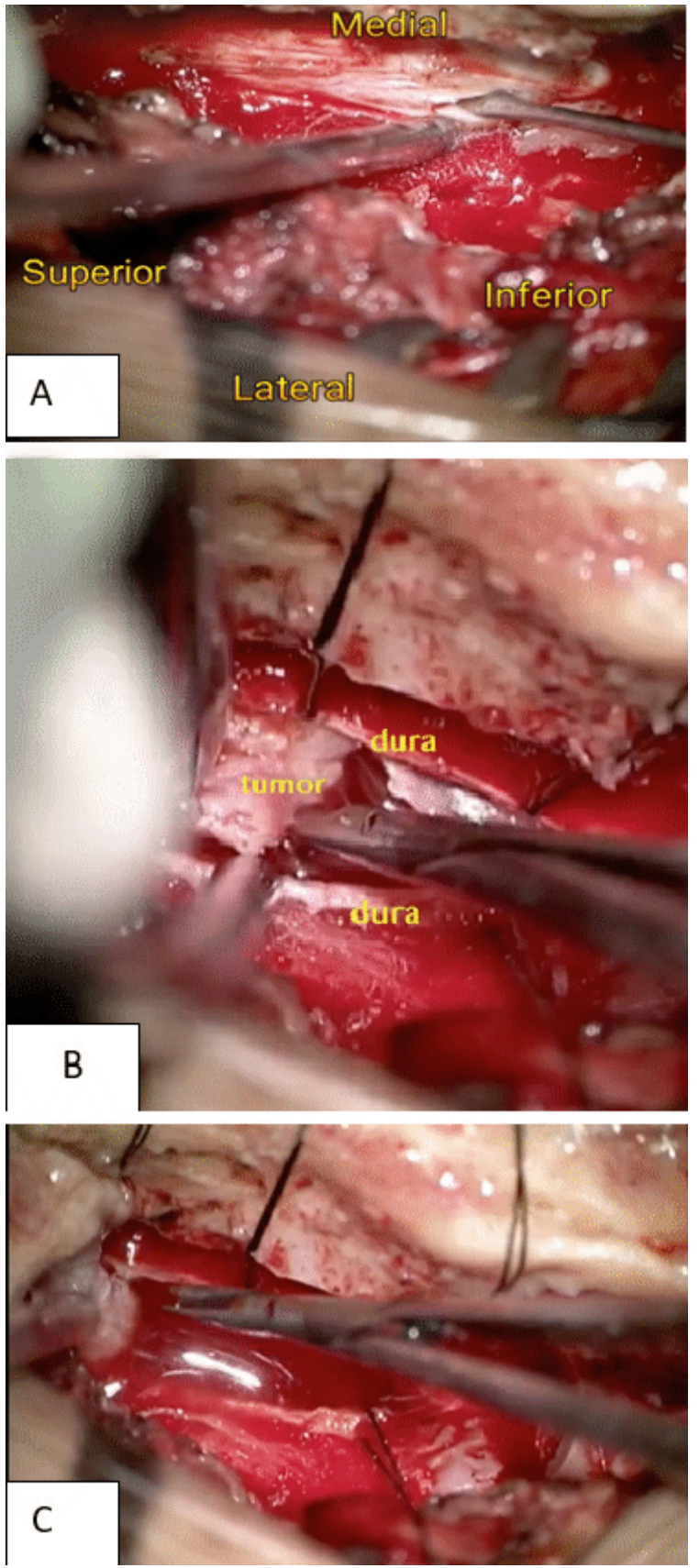

Fig 2. Intraoperative Photographs. (A) incision of the dural; (B) excision intradural-extramedullary tumor; (C) total excision of the tumor
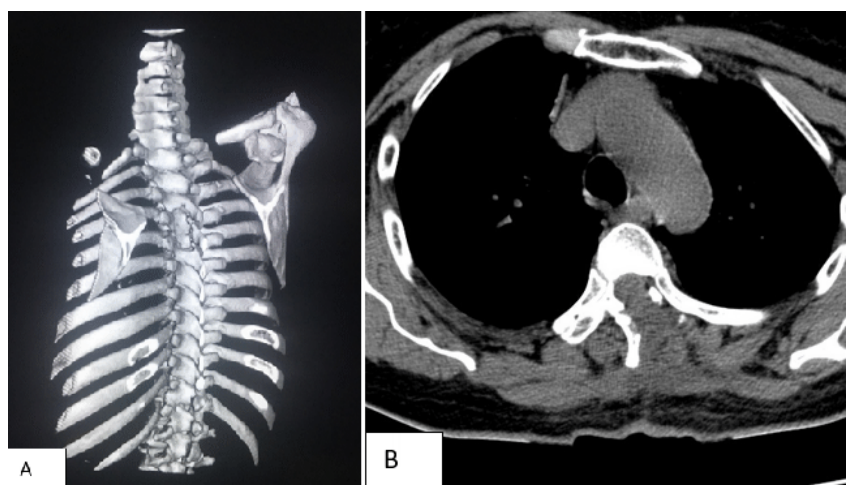

Fig 3. Post-Operative CT Scan A) With three-dimensional reconstruction, revealed unilateral defect at thoracic 3 to thoracic 5 level; B) Axial CT Scan showed the defect of the thoracic spine on the left side

findings in excised tissue revealed a meningioma, hence we educated the patient and family about the recurrence of spinal meningioma 
tumor.

One week later she came back for a check-up, and she already have improvement in motoric power, her sensoric and autonomic function found to be normal as it to be before the surgery. Postoperative pain at the location of the incision mark has been greatly reduced and the patient is satisfied with the results of the operation she has undergone.

\section{Discussion}

Intradural-extramedullary tumors accounted in primary spinal tumor and most of the intradural-extramedullary spinal tumors are benign with meningioma and schwannoma as the most common pathological finding for this type of tumor. ${ }^{1,2}$

Conventionally, intradural-extramedullary spinal tumors were managed through excision with total laminectomy approach. This approach will facilitate proper visualization for the surgeon. ${ }^{3,4,6}$

In the other side, total laminectomy lead to several complications. It produces overt spinal instability leading to spinal deformity, and fibrosis. The integrity of posterior column such as ligamentum flavum, supraspinous and interspinous ligament will be deteriorate caused by iatrogenic surgery damage. According to the reports, kyphosis was found as the most common complication in a total laminectomy. ${ }^{4,6,7}$ Damage to posterior column integrity was considered to play an important role that caused kyphosis. Kyphosis related laminectomy may occur within weeks to years after the procedure for trauma or tumor, especially in children. The incidence of spinal instability following total laminectomy has been reported fewer in adults compared to children $(20 \%$ vs $45 \%)$. $^{3-10}$

Other complications following laminectomy are progressive neurological deficit and pain that mainly caused by compression of the spinal cord or nerve roots or by epidural scarring. ${ }^{5}$ Other complications observed from total laminectomy include progressive myelo pathy, lack of bone protection over the spinal cord, less protection of hematoma, epidural scarring and fibrosis as well as difficulty if required second surgery. ${ }^{3,4,7,8,11}$

To reduce complications following total laminectomy, various operative technique was developed. Laminoplasty aimed to overcome post-operative instability and preventing epidural scar formation. However, laminoplasty is not benefecial in maintaining postoperative stability as it can still disrupt posterior ligamentous structures. Therefore it has been recommended to fuse the spine at the initial laminectomy to reduce postoperative complications. Due to the disadvantages of laminectomy, a minimally invasive technique has also been emphasized for spinal surgery, and it was popularized by Eggert et al., ${ }^{4}$ In 1991, Yasargil et al., suggested the new technique of laminectomy by unilateral hemilaminectomy. They perform this procedure in 20 patients and found none exhibited spinal instability after two years of follow-up..$^{3,4,6,8,11}$ Chiou et al., reported that patients undergoing microsurgical resection of spinal tumors using hemilaminectomy demonstrated fewer postoperative complication with shorter hospital stay. $3,4,7,11$

Important things to remember, unilateral laminectomy has a high degree of difficulty and it needs an experienced neurosurgeon to perform this procedure. It is very difficult to extirpate the attachment of dura that located centrally through a limited surgical exposure and may result in damage to the branches of nerve roots and spinal cords. Therefore, this procedure is recommended for spinal tumors located dorsal-laterally, and ventral-laterally, especially in patients with spinal neurinoma and meningioma. ${ }^{12}$

In our case, we performed unilateral laminectomy at T4 vertebral levels on the left side. The main issue to perform this technique is surgical exposure and difficulty to handle instruments. We found that unilateral laminectomy combines with good patient positioning will provide good exposure to the spinal canal and help the surgeon to perform and manipulate spinal tumors, the view for our patient was sufficient and the tumor was clearly identified and fully exposed. Although spinal meningioma has high recurrence rate, we succesfully resected the tumor and coagulated the dural origin. Post-operative care is the main advantage for unilateral laminectomy, such as reduces postoperative pain, early mobilization, less blood loss, prevents instability and shorter hospital stays.

\section{Conclusion}

Management for Intradural-Extramedullary spinal tumor at thoracic 4 vertebrae, was surgical unilateral laminectomy with total excision of the tumor without any fusion or stabilization. By positioning the patient appropriately we had a very optimal view over the surgery field. Fast improvement of patient condition, minimally pain after surgery, no blood transfusion was needed, shorter intensive care period needed and fast recovery time are the prominent things in this case. We conclude that unilateral laminectomy was the best surgical treatment for intradural-extramedullary spinal tumor considering the fast recovery time.

\section{Acknowledgement}

None

\section{References}

1. Govind M, Radheshyam M, Achal S, et al. Intradural Extramedullary Spinal Cord Tumors: a Retrospective Study at Tertiary Referral Hospital. Romanian Neurosurgery. 2016;1:106-12. DOI: 10.1515/romneu-2016-0017

2. Greenberg MS. Handbook of Neurosurgery. In: Tumors of the Spine and Spinal Cord. Eighth Edition. Canada, Thieme; 2016, pp 783-92.

3. Gu R, Liu JB, Xia P, et al. Evaluation of Hemilaminectomy Use in Microsurgical Resection of Intradural Extramedullary Tumors. Oncology Letters. 2014;7: 1669-72. DOI: 10.3892/ol/2014/1949

4. Sim JE, Noh SJ, Song YJ, et al. Removal of Intradural-Extramedullary Spinal Cord Tumors with Unilateral Limited Laminectomy. J Korean Neurosurg Soc. 2008;43:232-6. DOI: 10. 3340/jkns.2008.43.5.232 
5. Lee JH, Jang JW, Kim SH, et al. Surgical Results after Unilateral Laminectomy for the Removal of Spinal Cord Tumors. Korean J Spine. 2012; 9(3):232-8. DOI: 10.14245/kjs.2012.9.3.232

6. Kankane VK, Gupta N, Sharma V. Surgical Outcome of Spinal Intradural Extramedullary Tumors: A Single-center Prospective Study of 92 Cases Assessment using Nurick's Grade and Visual Analog Scale. The Journal of Spinal Surgery. 2018; 5(2):63-8. DOI: 10.5005/jp-journals-10039-1172

7. Mathew D, Abraham TR, Nair AR. Microsurgical Management of Intraspinal Tumors in the Lumbar Spine: Hemilaminectomy as an Alternative to Laminectomy. Journal of Spinal Surgery. 2014; 1(2):84-90. DOI: 10.5005/jp-journals-10039-1017

8. Yeo DK, Im SB, Park KW, et al. Profiles of Spinal Cord Tumors Removed Through a Unilateral Hemilaminectomy. J Korean Neurorug Soc. 2011; 50:195-200. DOI: 10.3340/jkns.2011.50.3.195

9. Mahadewa TGB, Maliawan S, Sudewi AAR, et al. A comparative study of bilateral laminotomy and laminectomy with fusion for lumbar stenosis. Neurology Asia. 2010; 15(2): 153-8. Available from: https://www. researchgate.net/publication/280040071_A_comparatifve_study_of_bilateral_laminotomy_and_laminectomy_with_fusion_for_lumbar_stenosis

10. Mahadewa TGB. Laminoplasty fusion for cervical spinal cord injury with ossification of posterior longitudinal ligament: Combination technique for better result (Case Series). Bali Medical Journal. 2015; 4(3): 136-9. DOI : 10.15562/bmj.v4i3.155

11. Onyia CU, Menon SK. Surgical Technique for Managing Intradural Spinal Tumors: An Overview and Update. The Journal of Spinal Surgery. 2015; 2(3): 85-96. DOI: 10.5005/jp-journals-10039-1062

12. Sun CX, Meng XL, Xie SN, et al. Unilateral Hemilaminectomy for Patients with Intradural Extramedullary Tumors. J Zhejiang Univ-Sci B. 2011; 12(7): 575-81. DOI: 10.1631/jzus.B1000402 